\title{
A Multi-objective Harmony Search Algorithm for Optimal Energy and Environmental Refurbishment at District Level Scale
}

\author{
Diana Manjarres ${ }^{1}$, Lara Mabe ${ }^{1}$, Xabat Oregi ${ }^{1}$, Itziar Landa-Torres ${ }^{1}$, and \\ Eneko Arrizabalaga ${ }^{1}$ \\ TECNALIA Research \& Innovation, E-48160 Derio, Spain, \\ \{diana.manjarres, lara.mabe, xabat.oregi,itziar.landa, eneko.arrizabalaga\} \\ Qtecnalia.com
}

\begin{abstract}
Nowadays municipalities are facing an increasing commitment regarding the energy and environmental performance of cities and districts. The multiple factors that characterize a district scenario, such as: refurbishment strategies' selection, combination of passive, active and control measures, the surface to be refurbished and the generation systems to be substituted will highly influence the final impacts of the refurbishment solution. In order to answer this increasing demand and consider all above-mentioned district factors, municipalities need optimisation methods supporting the decision making process at district level scale when defining cost-effective refurbishment scenarios. Furthermore, the optimisation process should enable the evaluation of feasible solutions at district scale taking into account that each district and building has specific boundaries and barriers. Considering these needs, this paper presents a multi-objective approach allowing a simultaneous environmental and economic assessment of refurbishment scenarios at district scale. With the aim at demonstrating the effectiveness of the proposed approach, a real scenario of Gros district in the city of Donostia-San Sebastian (North of Spain) is presented. After analysing the baseline scenario in terms of energy performance, environmental and economic impacts, the multi-objective Harmony Search algorithm has been employed to assess the goal of reducing the environmental impacts in terms of Global Warming Potential (GWP) and minimizing the investment cost obtaining the best ranking of economic and environmental refurbishment scenarios for the Gros district.
\end{abstract}

Keywords: energy, environmental, refurbishment, district, multi-objective, optimization

\section{Introduction}

Energy security and climate change are driving a future that implies important improvements in the energy performance of the building sector. The $28 \mathrm{Member}$ States of the European Union (EU) have set a Global Warming Potential (GWP) 
reduction target of $20 \%$ by 2020 , which has to be reached mainly through energy efficiency measures [1]. The building sector is one of the major sources of environmental impacts worldwide, as well as in the EU.

In order to support the energy transition of EU towards a low carbon economy, municipalities have a key role to play. Within the Covenant of Mayors initiative, thousands of local and regional authorities voluntarily committed to implement EU climate and energy objectives on their territory [2]. A Sustainable Energy Action Plan (SEAP) [3] is the key document in which the Covenant signatory outlines how it intends to reach its CO2 reduction target by 2020 . Through the development of SEAPs, local and regional authorities have defined targets and developed plans and choose specific energy efficiency measures to attempt these targets.

However, there is a lack of connection between global objectives at city level and the implementation of energy strategies at district level. Specific solutions defined at global scale usually underestimate barriers at district and building level. Besides, the introduction into the decision making process of different factors, such as: $\mathrm{CO} 2$ emissions and budget, greatly complicates the problem.

In this framework, authors in [4] present an evolutionary multi-objective optimization algorithm (NSGA-III) that optimizes four objectives at a time for a public school retrofit planning. Among the diverse options and alternatives found in the literature for generating appropriate retrofit scenarios, the aspects considered herein are: (1) minimize energy consumption; (2) minimize CO2 emissions; (3) minimize retrofit costs; and (4) maximize thermal comfort. Additionally, population-based meta-heuristic algorithms including Non-dominated Sorting Genetic Algorithm II (NSGA-II), Pareto-Archived Evolution Strategy (PAES) and Particle Swarm Optimization (PSO), have been found in a number of building optimization studies ([5],[6]). Also related to multi-objective genetic based algorithms, the work in [7] proposes two improvement strategies for building system design optimization. With the aim of modifying the behavior of conventional evolutionary algorithms, adaptive operators and the meta-model approach have been modified in order to improve the optimization convergence and speed performance. Along the optimization process, a set of optimal solutions are generally generated; as this process usually takes a number of energy simulations at each generation, the optimization time of this algorithms in retrofit planning problems is increased. Improvement of this process includes tuning algorithm parameters and hybrid local search algorithms with meta-heuristic algorithms ([8], [9]). Tuning parameters is unfeasible in actual case studies since one optimization process can take days to complete. The other approach based on hybrid optimization algorithms, try to narrow down the search space and utilize fast and accurate gradient-based search algorithms to converge on the optimal region ([10], [11]).

In this regard, this paper advances over the state of the art by proposing a novel multi-objective heuristic method based on the Harmony Search algorithm specially tailored for obtaining optimal refurbishment solutions at district level. Although the presented approach can be used for different municipalities 
and indicators according to specific policy goals, a case study of the district of Gros in Donostia-San Sebastian (Spain) is employed in which two different objectives are considered: 1) the maximization of the reduction of $\mathrm{CO} 2$ emissions (i.e. minimization of the GWP) and 2) the minimization of the initial economic investment.

\section{Gros District Case Study Definition}

The district of Gros (Figure 1) is selected for the case study due to its representativeness for the city as the east enlargement of it that has progressively gained space to the river and to the sea. Moreover, Gros is one of the most chaotic examples of the urbanism of Donostia - San Sebastian with very irregular blocks and a maze of streets saturated by a mix of uses of its ground floors (commercial, workshops, garages and small industries that are being gradually replaced by new residential buildings). These characteristics combined with other aspects, such as: the different ages, thermal properties, energy generation systems and protection level of its buildings, offer an ideal context for the development of a broad variety of scenarios for the retrofit optimization process.

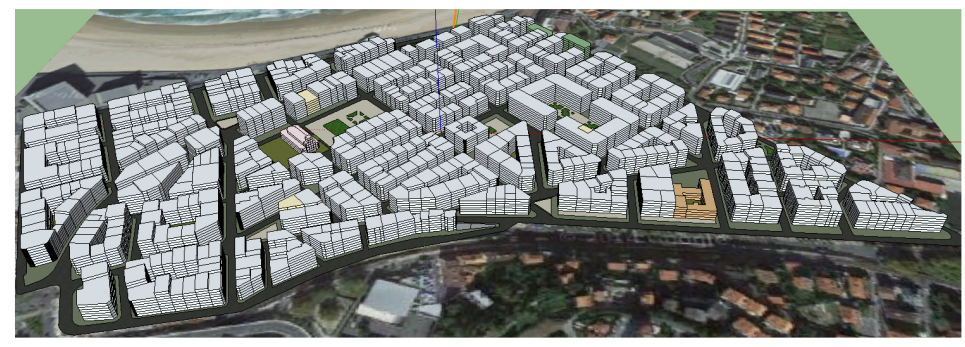

Figure 1. Screenshot of the Gros district case study. The modelization and the environmental assessment has been carried out by NEST tool [12].

The information obtained in close collaboration with the city of DonostiaSan Sebastian (see Table 1) enabled the definition of the majority of required inputs for modelling and assessing the baseline scenario of Gros district. Some of this data is based on assumptions from previous studies [12].

Table 2 shows the main characteristics of Gros district regarding the relationship between the energy certification of the buildings, their Energy Demand (ED), the quantity of buildings, the Heated Floor Area (HFA) and the amount of surface per building typology. The residential buildings analyzed for the district of Gros have been grouped depending on their efficiency level, their energy consumption per final use and other building envelope characteristics indicated in Table 2. The systems considered for the calculation of heating and Domestic Hot Water (DHW) consumptions are gas boilers for the buildings with a building typology between $\mathrm{C}$ and $\mathrm{E}$ and electricity for a building typology between $\mathrm{F}$ 
and G. Finally, due to the climatic zone of Donostia-San Sebastian no cooling system has been considered for residential buildings.

Table 2 shows that the energy labelling level of the $92 \%$ of the buildings of Gros in less than the D energy rating. That is, the energy and environmental performance of the $92 \%$ of the buildings is worse than the limit value defined by the Spanish legislation. Based on these baseline values of the district of Gros, it is necessary to evaluate, optimize and apply different refurbishment strategies to improve their energy and environmental performance.

Table 1. Summary of aspects of the district of Gros.

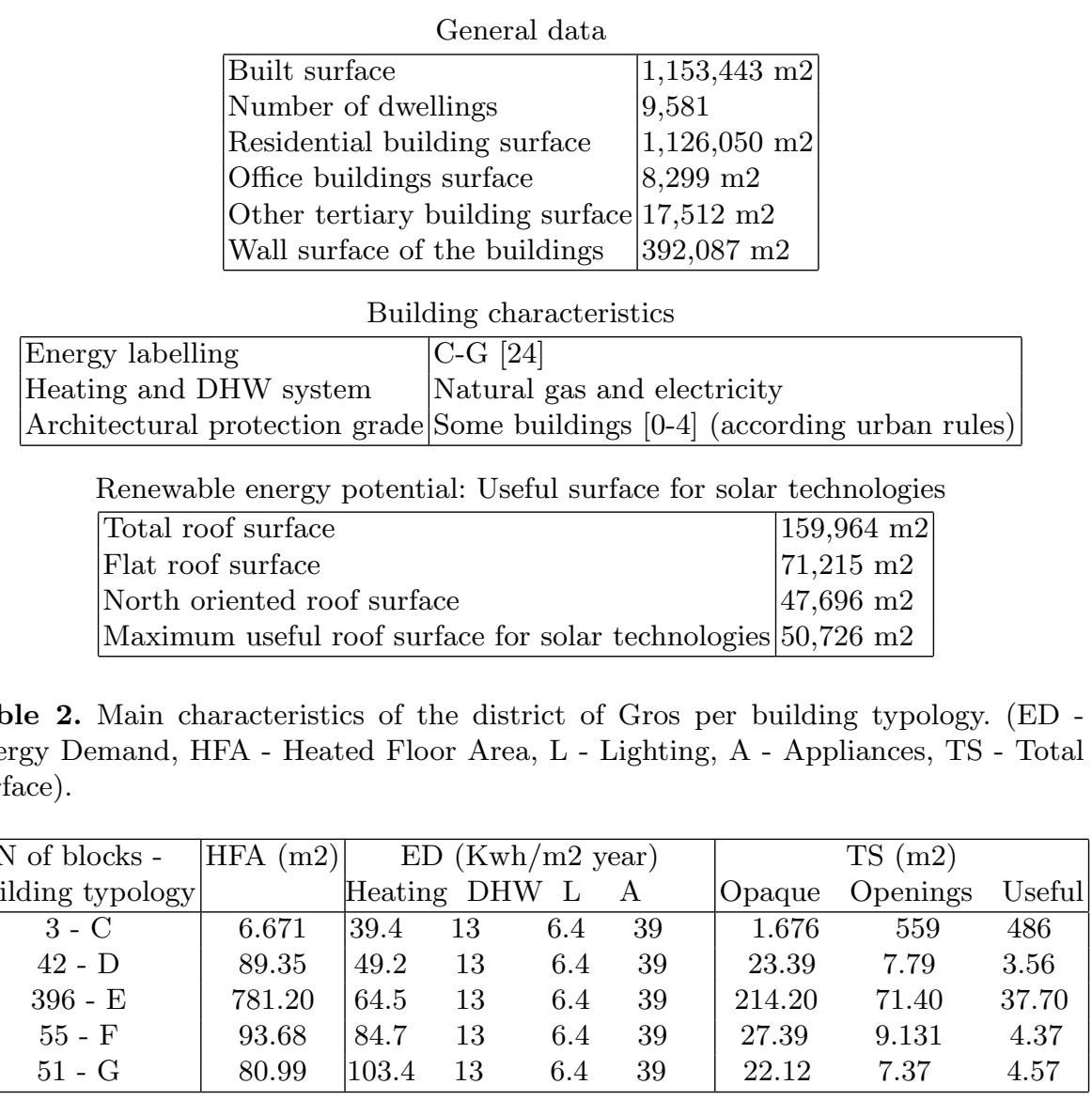

\section{District Energy Retrofitting Problem Formulation}

As stated in previous section, the majority of buildings of Gros district has a poor energy labelling level (below D). Therefore, it is of great importance 
to obtain optimal district retrofitting solutions in terms of cost-effective and $\mathrm{CO} 2$ efficient designs. In order to accomplish this, this paper proposes a multiobjective heuristic approach that simultaneously minimize the investment cost and the GWP while considering a set of different constraints between the selected refurbishment strategies.

Despite the numerous existing technologies for energy refurbishment and the current trends towards "Net Zero Energy Buildings" [25], this work is limited to assessing only most common approaches.

In the case of the passive refurbishment strategies, two different efficiency levels per each refurbishment strategy are however proposed to take into account trends toward more energy efficient buildings: basic (b) and advanced (a) levels. The basic efficiency level is based on refurbishment strategies that enforce the minimum thermal requirements determined by the existing regulations and standards. The advanced efficiency level strategies improve the building thermal properties to very high values, such as those used in standards like the Passive House [26].

The first solutions $(1 \mathrm{~B}, 1 \mathrm{~A})$ corresponds to ventilated facade system, which is composed of an aluminum substructure, a layer of insulation and a ceramic outlayer. The second strategy $(2 \mathrm{~B}, 2 \mathrm{~A})$ is an indoor thermal improvement solution consisting of a layer of insulation and plasterboard. Different insulation thicknesses are proposed for basic $(1 \mathrm{~B}, 2 \mathrm{~B})$ and advanced $(1 \mathrm{~A}, 2 \mathrm{~A})$ efficiency levels. The projected insulation thicknesses for the basic efficiency energy level are $5 \mathrm{~cm}$ for the fasade, $8 \mathrm{~cm}$ for the deck and $6 \mathrm{~cm}$ for the first floor slab. The thicknesses proposed for the advanced energy efficiency level are 25, 30 and 15 $\mathrm{cm}$, respectively.

The third refurbishment strategy $(3 \mathrm{~B}, 3 \mathrm{~A})$ focuses on the replacement windows with a new frame and glazing. The windows for the basic energy efficiency level (3B) consist of a double glazing $(2.7 \mathrm{~W} /(\mathrm{m} 2 \mathrm{~K}))$ and aluminum frame $(2.9$ $\mathrm{W} /(\mathrm{m} 2 \mathrm{~K}))$, meeting the minimum thermal requirements for refurbishments in Spain. The windows for advanced level (3A) consist of a low-emissivity coated glazing $(1.4 \mathrm{~W} /(\mathrm{m} 2 \mathrm{~K}))$ and wooden frames $(1.2 \mathrm{~W} /(\mathrm{m} 2 \mathrm{~K}))$.

Along with energy conservation refurbishment systems, this work has evaluated different strategies based on the use of energy from renewable sources. The first renewable strategy is the installation of a solar thermal system on the roof of the building (4), which uses solar energy to generate heat that is then used to produce hot water, reducing the electricity and natural gas use of current water heaters. The second renewable strategy (5) is the installation of photovoltaic panels on the roof of the building, generating and exporting electricity to the national grid.

Table 3 depicts a symmetric matrix representing the constraints for each refurbishment strategy . In this table, the set of strategies that can be jointly employed are represented by a value of 1 , whereas the strategies that cannot be applied together are represented by 0 . Note that in solar and photovoltaic strategies $(4,5)$ the total useful surface must be less that the $100 \%$ of the nonnorth oriented roof surface. 
Table 3. Symmetric matrix for refurbishment strategies' constraints.

\begin{tabular}{|c|c|c|c|c|c|c|c|c|}
\hline Refurbishment strategies & $1 \mathrm{~B}$ & $1 \mathrm{~A}$ & $2 \mathrm{~B}$ & $2 \mathrm{~A}$ & $3 \mathrm{~B}$ & $3 \mathrm{~A}$ & 4 & 5 \\
\hline 1B & 0 & 0 & 0 & 0 & 1 & 1 & 1 & 1 \\
1A & 0 & 0 & 0 & 0 & 1 & 1 & 1 & 1 \\
2B & 0 & 0 & 0 & 0 & 1 & 1 & 1 & 1 \\
2A & 0 & 0 & 0 & 0 & 1 & 1 & 1 & 1 \\
3B & 1 & 1 & 1 & 1 & 0 & 0 & 1 & 1 \\
3A & 1 & 1 & 1 & 1 & 0 & 0 & 1 & 1 \\
4 & 1 & 1 & 1 & 1 & 1 & 1 & 0 & 1 \\
5 & 1 & 1 & 1 & 1 & 1 & 1 & 1 & 0 \\
\hline
\end{tabular}

\section{Proposed Multi-objective Harmony Search Algorithm}

Let us start by briefly sketching the fundamentals of Harmony Search, which was first coined by Zong et al. in [27] and thereafter applied to a wide number of applications and problems, such as: the Combined Heat and Power Economic Dispatch problem (CHPED) [28], the Traveling Salesperson Problem (TSP) [29], tour routing [30], Sudoku puzzle solving [31], distribution of $24 \mathrm{~h}$ energency units [32] and Grouping problems [33], [34], among others.

This paper elaborates further on the multi-objective view of the problem and presents a two-objective Harmony Search algorithm that attempts at simultaneously minimizing two (possibly conflicting) fitness functions: Investment Cost (IC) and Global Warming Potential (GWP). By this way, instead of finding a single solution of the problem, it obtains a set of good compromises or tradeoffs called the Pareto optimal set. Due to the population-based rationale of the Harmony Search algorithm, it relies on a set of candidates $\{\mathbf{H}(k)\}_{k=1}^{K}$ (Harmony Memory), which are iteratively refined by means of intelligent combinations and mutations applied note-wise. Assuming the classical notation related to HS, we will hereafter refer to a possible candidate set $\mathbf{H}(k)$ as harmony or melody, whereas note denotes any of its compounding entries $h(k)$, with $k \in\{1, \ldots, K\}$. In our optimization framework, each melody encodes a refurbishment strategy for a building typology in the district $\in\{C, D, E, F, G\}$ and each note represents the percentage of application perc $\in\{0,10, \ldots, 100\} \%$ of each refurbishment strategy $\in\{1 B, 1 A, 2 B, 2 A, 3 B, 3 A, 4,5\}$.

The refinement procedure is controlled by three different parameters: 1$)$ the Harmony Memory Considering Rate, HMCR; 2) the Pitch Adjusting Rate, PAR and 3) the Random Selection Rate, RSR. After the improvisation procedure, the value of the two objective functions (IC and GWP) are separately computed for every improvised melody and the best (with respect to fitness values and spread) $K$ melodies - out of the newly produced ones and those from the previous iteration - compose the Harmony Memory for the next iteration. Note that this procedure is repeated until a fixed number of iterations $\mathcal{I}$ is completed. In the following, the steps of the proposed multi-objective HS algorithm are described in detail: 
A. The initialization process is only executed at the first iteration. At this step, the entries of the Harmony Memory $\mathbf{H}(k)$ are randomly generated within the range $\{0,10, \ldots, 100\}$ while meeting the constraints of the District Energy Retrofitting problem.

B. In the improvisation procedure, three different probabilistic operators are sequentially applied to each note so as to produce a new set of $K$ improvised harmonies, namely:

- The Harmony Memory Considering Rate, HMCR $\in[0,1]$, sets the probability that the new value for a certain note is drawn uniformly from the values of this same note in all the other $K-1$ melodies.

- The Pitch Adjusting Rate, PAR $\in[0,1]$, refers to the probability that the new value for a given note is taken from its neighbouring values. A step of $10 \%$ is added or subtracted with probability $\frac{1}{2}$.

- The Random Selection Rate, RSR $\in[0,1]$, establishes the probability to pick a random value for the new note from the subset $[0,10, \ldots 100]$.

C. The algorithm checks whether the newly improvised energy retrofitting solutions are valid in terms of active and passive refurbishment strategies. Regarding active strategies the sum of non-north oriented roof must be less or equal $100 \%$ and in all cases the district strategies' constraints (Table 3 ) must be fulfilled.

D. At each iteration the new generated candidate solutions are then evaluated in terms of both Investment Cost (IC) Equation (1) and reduction of Global Warming Potential (GWP) Equation (2).

$$
\begin{gathered}
I C=\sum_{k=0}^{K} h(k) \cdot c(k) \cdot A \\
G W P=\sum_{k=0}^{K} \frac{h(k) \cdot H D(k) \cdot E H(K) \cdot A \cdot \rho_{G W P}}{\rho},
\end{gathered}
$$

where $h(k)$ represents a note in the harmony memory, $c(k)$ the cost value per refurbishment startegy, $A$ the area of useful surface per strategy, i.e. opaque $(1 \mathrm{~B}, 1 \mathrm{~A}, 2 \mathrm{~B}, 2 \mathrm{~A})$ or openning $(3 \mathrm{~B}, 3 \mathrm{~A})$ surfaces or non-north oriented surfaces $(4,5), H D(K)$ the heating demand reduction after the application of the strategies, $E H(K)$ the energy consumption associated to heating demand, $\rho_{G W P}$ the GWP factor per thermal generation system and $\rho$ the performance of the thermal generation system.

Based on such metric values, a rank and a crowding distance value are assigned at each solution (as explained in [35]). Candidate solutions with less rank value and largest crowding distance value are preferred in order to fill the harmony memory for subsequent iterations. That is, between two solutions with different non-domination ranks, the point with the lower rank is selected. Otherwise, if both of them belong to the same front, then the point located in a region with lesser number of solutions (larger crowding distance) is preferred. If $n$ Iter $<\mathcal{I}$, the algorithm iterates by setting $n$ Iter $=n$ Iter +1 and by returning to step B. Otherwise, the algorithm stops and the set of 
candidate solutions that conformed the dominant pareto front is given as possible outcomes of the energy retrofitting solution.

\section{Simulation Results}

In order to obtain the optimal refurbishment scenarios in terms of investment cost and reduction of GWP, the Multi-Objective HS algorithm has been applied at each building typology representing the Gros case study. Figure 2 depicts the Pareto front approximation per building typology after 20 Monte Carlo simulations in terms of initial economic investment $(€ / \mathrm{m} 2)$ for the avoided GWP $(\mathrm{kg}$ $\mathrm{CO} 2$ eq. $/ \mathrm{m} 2$ year). The Pareto front has been expressed in unit of surface in order to allow comparing the cost-effectiveness of the scenarios at each building typology.

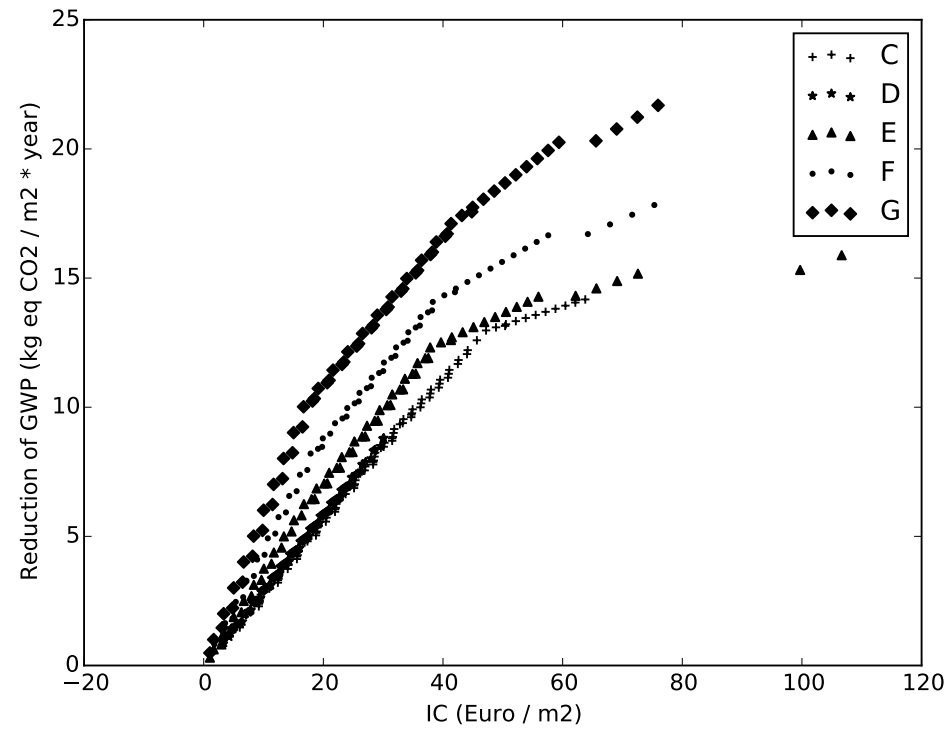

Figure 2. Pareto front approximation of each building typology in terms of IC $(€ / \mathrm{m} 2)$ and reduction of GWP (kg CO2 eq./m2 year).

It can be inferred that most efficient building typologies (building typologies $\mathrm{C}$ and $\mathrm{D}$ ) have less cost-effective refurbishment potential than building typologies with a worse energy labelling $(\mathrm{E}, \mathrm{F}, \mathrm{G})$. The algorithm proposes the application of internal thermal insulation and solar thermal panels implementation as the less initial economic investment solutions. Once the maximum surface has been covered by both solutions, the algorithm adds the replacement of windows. Within the Pareto Front, some scenarios for building typologies C and D accept 
the implementation of solar thermal panels without the application of passive strategies. It is known [36] that for buildings with a good thermal insulation, renewables can be a most cost-effective solution to achieve environmental goals than passive strategies.

Table 4. Investment cost and scenario description for specific GWP reduction goals for each building typology.

GWP reduction: $5 \mathrm{~kg}$ CO2 eq. $/ \mathrm{m} 2$ year

\begin{tabular}{|c|c|c|}
\hline Building typology & $\mathrm{IC}(€ / \mathrm{m} 2)$ & Refurbishment scenario \\
\hline $\mathrm{C}$ & 18.85 & $\begin{array}{c}60 \%(2 \mathrm{~B}) \\
+30 \%(4)\end{array}$ \\
\hline $\mathrm{D}$ & 17.49 & $70 \%(2 \mathrm{~B})$ \\
& & $+20 \%(4)$ \\
\hline $\mathrm{E}$ & 13.40 & $80 \%(2 \mathrm{~B})$ \\
\hline $\mathrm{F}$ & 11.96 & $60 \%(2 \mathrm{~B})$ \\
& & $+10 \%(5)$ \\
\hline $\mathrm{G}$ & 8.34 & $50 \%(2 \mathrm{~B})$ \\
\hline
\end{tabular}

GWP reduction: $13 \mathrm{~kg}$ CO2 eq. $/ \mathrm{m} 2$ year

\begin{tabular}{|l|l|l|}
\hline Building typology & $\mathrm{IC}(€ / \mathrm{m} 2)$ & Refurbishment scenario \\
\hline
\end{tabular}

\begin{tabular}{|c|c|c|}
\hline $\mathrm{C}$ & 50.52 & $\begin{array}{c}100 \%(2 \mathrm{~B}) \\
+100 \%(4) \\
+10 \%(5)\end{array}$ \\
\hline $\mathrm{D}$ & $\mathrm{N} . \mathrm{A}$ & $\mathrm{N} . \mathrm{A}$ \\
\hline $\mathrm{E}$ & 37.86 & $100 \%(2 \mathrm{~B})$ \\
& & $+100 \%(4)$ \\
\hline $\mathrm{F}$ & 36.25 & $100 \%(2 \mathrm{~B})$ \\
& & $+90 \%(4)$ \\
\hline $\mathrm{G}$ & 25.58 & $100 \%(2 \mathrm{~B})$ \\
& & $+30 \%(4)$ \\
\hline
\end{tabular}

GWP reduction: $18 \mathrm{~kg}$ CO2 eq. $/ \mathrm{m} 2$ year

Building typology $\mathrm{IC}(€ / \mathrm{m} 2)$ Refurbishment scenario

\begin{tabular}{|c|c|c|}
\hline C & N.A & N.A \\
\hline D & N.A & N.A \\
\hline E & N.A & N.A \\
\hline F & 104.24 & $100 \%(2 \mathrm{~B})$ \\
& & $+100 \%(4)$ \\
& & $+80 \%(3 \mathrm{~B})$ \\
\hline G & 46.76 & $100 \%(2 \mathrm{~B})$ \\
& & $+100 \%(4)$ \\
& & $+30 \%(3 \mathrm{~A})$ \\
\hline
\end{tabular}

For building typologies $\mathrm{E}, \mathrm{F}$ and $\mathrm{G}$ the evolution is different than for the most efficient ones (C, D) described previously. In this case, the algorithm proposes a thermal internal insulation until covering the whole opaque surface area. With a higher investment cost, the thermal internal insulation is complemented with solar thermal panels implementation. Once the hundred percent of useful roof's 
surface and of the opaque surface are covered, the replacement of windows is proposed. Finally, it also infers scenarios replacing the thermal internal insulation strategy by the external one that implies more initial economic investment per surface area but higher insulation potential.

In order to explain in more detail the results obtained, Table 4 shows the scenarios obtained by the algorithm for each building typology considering a low, a medium and a high GWP reduction. It can be shown that for buildings with better energy labelling, a higher investment cost is required to achieve the same CO2 savings.

Finally, regarding the final cost-effective energy refurbishment scenarios at district level, Table 5 depicts the obtained solutions for each building typology in order to acquire a GWP reduction goal of $20 \%, 30 \%$ and $50 \%$.

Table 5. Final cost-effective energy refurbishment scenarios to achieve GWP reduction goals at district level.

\begin{tabular}{|c|c|c|c|}
\hline & $\begin{array}{c}\text { GWP reduction: } 20 \% \\
\text { IC }=15.67 \mathrm{M} € \\
\text { GWP red.=6,504 } \\
\text { tn CO2 eq. } / \text { year })\end{array}$ & $\begin{array}{c}\text { GWP reduction: } 30 \% \\
\text { IC }=25.19 \mathrm{G} € \\
\text { GWP red. }=10,150 \\
\text { (tn CO2 eq. } / \text { year })\end{array}$ & $\begin{array}{c}\text { GWP reduction: } 50 \% \\
\text { IC }=56.42 \mathrm{M} € \\
\text { GWP red. }=14,883 \\
\text { (tn CO2 eq. } / \text { year })\end{array}$ \\
\hline $\mathrm{C}$ & $40 \%(2 \mathrm{~B})+20 \%(4)$ & $20 \%(2 \mathrm{~B})+60 \%(4)$ & $40 \%(2 \mathrm{~B})+20 \%(4)$ \\
\hline $\mathrm{D}$ & $40 \%(2 \mathrm{~B})+70 \%(4)$ & $50 \%(2 \mathrm{~B})+40 \%(4)+10 \%(5)$ & $100 \%(2 \mathrm{~B})+20 \%(4)$ \\
\hline $\mathrm{E}$ & $80 \%(2 \mathrm{~B})$ & $100 \%(2 \mathrm{~B})+60 \%(4)$ & $100 \%(2 \mathrm{~B})+100 \%(4)$ \\
& & $+10 \%(5)$ & $100 \%(3 \mathrm{~A})$ \\
\hline $\mathrm{F}$ & $100 \%(2 \mathrm{~B})+20 \%(4)$ & $100 \%(2 \mathrm{~B})+30 \%(4)$ & $\begin{array}{c}100 \%(2 \mathrm{~B})+100 \%(4) \\
+80 \%(3 \mathrm{~B})\end{array}$ \\
\hline $\mathrm{G}$ & $100 \%(2 \mathrm{~B})+70 \%(4)$ & $100 \%(2 \mathrm{~B})+10 \%(4)$ & $100 \%(2 \mathrm{~B})+100 \%(4)$ \\
& & $+10 \%(3 \mathrm{~A})$ & $+80 \%(3 \mathrm{~A})$ \\
\hline
\end{tabular}

\section{Concluding remarks}

This paper proposes a Multi-Objective HS algorithm for the optimal district's energy refurbishment design. The developed approach is applied to a real case study of Gros in order to define the best energy refurbishment scenarios to reach different GWP reduction goals. The achieved results elucidates the goodness of the proposed Multi-Objective HS algorithm during a district refurbishment's decision making process. It is capable of obtaining a wide range of feasible scenarios in terms of environmental aspects and economic investment allowing the selection of the optimal scenario considering the available budget and the architectural boundaries. Even if the robustness of this algorithm is rigurously assessed within this paper, the scope of the study can be extended by means of including more refurbishment strategies and boundaries. This approach will be developed within the OptEEmAL project [37] where the Multi-Objective HS algorithm will be integrated within a platform that will allow its interoperability with the Energy Conservation Measures database developed in the project in which the objective functions will be calculated with a simulation module based on Energyplus [18]. 


\section{Acknowledgment}

Part of this work was developed from results obtained during the "Optimised Energy Efficient Design Platform for Refurbishment at District Level" (OptEEmAL) project, Grant Agreement Number 680676.

\section{References}

1. Directive 2010/31/EU. European parliament and of the council of 19 May 2010 on the energy performance of buildings

2. Covenant of Mayors for Climate \& Energy. Available at: http://www . covenantofmayors.eu/The-Covenant-of-Mayors-for-Climate.html

3. Minuartia Enea, RSM Gasso Auditores , CIMNE, 2011. Sustainable Energy Action Plan of Donostia. Available at: http://www.donostia.eus/info/ciudadano/ ma_areas.nsf/voWebContenidosId/80FE86B9FAB3DD7DC1257FF6002C5878/

4. Son, H., Kim, C.: Evolutionary Multi-objective Optimization in Building Retrofit Planning Problem. Procedia Engineering, vol. 145, pp. 565-570, 2016

5. Machairas, V., Tsangrassoulis, A., Axarli, K.: Algorithms for optimization of building design: a review, Renew. Sustain. Energy Rev. vol. 31, pp. 101112, 2014

6. Karaguzel, O.T., Zhang, R., Lam, K.P.: Coupling of whole-building energy simulation and multi-dimensional numerical optimization for minimizing the life cycle costs of office buildings Building Simulation, vol. 7, Springer , pp. 111121, 2014

7. Xu, W., Chong, A., Karaguzel, O. T., Lam, K. P.: Improving evolutionary algorithm performance for integer type multi-objective building system design optimization. Energy and Buildings, vol. 127, pp. 714-729, 2016

8. Alajmi A., Wright J.: Selecting the most efficient genetic algorithm sets insolving unconstrained building optimization problem, Int. J. Sustain. Built Environ. vol. 3, no. 1, pp. 1826, 2014.

9. Nguyen, A.T., Reiter, S., Rigo, P.: A review on simulation-based optimization methods applied to building performance analysis, Appl. Energy, vol. 113, 10431058, 2014

10. Greiner, D., Galvan, B., Periaux, J., Gauger, N., Giannakoglou, K., Winter, G.: Advances in Evolutionary and Deterministic Methods for Design, Optimization and Control in Engineering and Sciences, Springer, 2015

11. Juan, Y.K., Gao, P., Wang, J.: A hybrid decision support system for sustainable office building renovation and energy performance improvement, Energy Build. vol.42, no.3, pp. 290297, 2010

12. Oregi, X., Pousse, M., Mabe, L., Escudera, A., Mardaras, I.; Sustainability assessment of three districts in the city of Donostia through the NEST simulation tool. Natural Resources Forum (2016). doi: http://dx.doi.org/10.1111/1477-8947.12104, 2016.

13. GeoEuskadi. Available at: http://www.geo.euskadi.net/s69-bisorea/es/ x72aGeoeuskadiWAR/index.jsp

14. Cadaster of Gipuzkoa. Available at: http://www4.gipuzkoa.net/ogasuna/ catastro

15. Basque Government. Energy Efficiency Certificate. Available at: http://www. industria.ejgv.euskadi.eus/r44-in0100/es/contenidos/informacion/

16. Ministry of Housing, 2013a. Order FOM/1635/2013, of 10th September. CTEDB-HE technical building code energy saving document updated. BOE n 219, 12 September. 
17. Design Builder Simulation Tool. Available at: http://www.designbuilder.es

18. Energy Plus Energy simulation tool. U.S. Department of Energys (DOE) Building Technologies Office (BTO). Available at: https://energyplus.net/

19. ASHRAE. International Weather Files for Energy Calculations 2.0 (IWEC2). Available online: https://www.ashrae.org/resources--publications/

20. CTE, 2013. Spanish Technical Building Code. Available at: http://www . codigotecnico.org/

21. Metz, B., Davidson, O., Bosch, P., Dave, R., Meyer, L.: Contribution of Working Group III to the Fourth Assessment Report of the Intergovernmental Panel on Climate Change. Cambridge University Press, Cambridge, New York, USA, 2007.

22. Weidema BP, Bauer C, Hischier R, Mutel C, Nemecek T, Reinhard J, Vadenbo CO, Wernet G., 2013. Overview and methodology. Data quality guideline for the ecoinvent database version 3. Ecoinvent Report 1(v3). St. Gallen: The ecoinvent Centre.

23. REE, 2015. Spain Electricity Network. Available at: http://www.ree.es/en

24. Ministry of Housing. Royal Decree 235/2013, 5th of April 2013, approving the Spanish Energy Certification of Buildings. BOE n89, 13th April.

25. Cellura, M., Guarino, F., Longo, S., Mistretta, M.: Different energy balances for the redesign of nearly net zero energy buildings: An Italian case study, Renewable and Sustainable Energy Reviews, Volume 45, May 2015, Pages 100-112.

26. IPHA. International Passive House Association. Available online: http://www. passivehouse-international.org/

27. Z. W. Geem, J. Hoon Kim and G. V. Loganathan.: A New Heuristic Optimization Algorithm: Harmony Search, Simulation, vol. 76, no. 2, pp. 60-68, 2001.

28. A. Vasebia, M. Fesangharyb and S.M.T. Bathaeea.: Combined heat and power economic dispatch by harmony search algorithm, International Journal of Electrical Power \& Energy Systems, vol. 29, no. 10, pp. 713-719, 2007.

29. Z. W. Geem, J. Hoon Kim and G. V. Loganathan.: A New Heuristic Optimization Algorithm: Harmony Search, Simulation, vol. 76, no. 2, pp. 60-68, 2001.

30. Z. W. Geem, C. L. Tseng and Y. Park.: Harmony Search for Generalized Orienteering Problem: Best Touring in China, Lecture Notes in Computer Science, vol. 3412, pp. 741-750, 2005.

31. Z. W. Geem, Harmony Search Algorithm for Solving Sudoku, Lecture Notes in Artificial Intelligence, vol. 4692, pp. 371-378, 2007.

32. Landa-Torres I. , Manjarres D., Salcedo-Sanz S., Del Ser J. and Gil-Lopez, S.: A Multiobjective Grouping Harmony Search Algorithm for the Optimal Distribution of 24-hour Medical Emergency Units. Expert Systems with Applications, vol. 40, no. 6, pp. 2343-2349, 2013.

33. Landa-Torres I., Del Ser J., Salcedo-Sanz S., Gil-Lopez S., Portilla-Figueras J. A. and Alonso-Garrido O.: A comparative study of two hybrid grouping evolutionary techniques for the capacitated P-median problem. Conputers \& Operations Research, vol. 39, no. 9, pp. 2214-2222, 2012.

34. Landa-Torres I., Gil-Lopez S., Del Ser J, Salcedo-Sanz S., Manjarres D. and Portilla-Figueras J. A.: Efficient citywide planning of open WiFi access networks using novel grouping harmony search heuristics. Engineering Applications of Artificial Intelligence. vol. 26, no. 3, pp. 11241130, 2013.

35. Kalyanmoy D., Agrawal S., Pratap A. and Meyarivan T.: A fast Elitist NonDominated Sorting Genetic Algorithm for Multi-Objective Optimization: NSGA-II. IEEE Transactions on Evolutionary Computation, vol. 6, no. 2, pp. 182-197, 2000. 
36. Oregi, X.: Techno-Economic Evaluation of Building Energy Refurbishment Processes from a Life Cycle Perspective. University of the Basque Country, Donostia, Spain, 2015.

37. Garcia-Fuentes, MA., Hernandez, G., Serna VI., Vicente, JM.: OptEEmAL: una herramienta de diseño para proyectos de rehabilitación en áreas urbanas hacia distritos de Energía Casi Nula. Congreso EECN III (Edificios Energía Casi Nulo). Junio, 2016. Madrid, Spain. ISBN: 978-84-608-8686-0, 2016. 